\title{
Current Transport Mechanism in Palladium Schottky Contact on Si-Based Freestanding GaN
}

\author{
Moonsang Lee ${ }^{1} \mathbb{1}$, Chang Wan Ahn ${ }^{2}$, Thi Kim Oanh Vu ${ }^{2}$, Hyun Uk Lee ${ }^{1}$, Yesul Jeong ${ }^{3}$, \\ Myung Gwan Hahm ${ }^{4, *}$, Eun Kyu Kim ${ }^{2, *}$ (D) and Sungsoo Park 5,6,* \\ 1 Research Center for Materials Analysis, Korea Basic Science Institute, Gwahak-ro 169-148, Yuseong-gu, \\ Daejeon 34133, Korea; lms1015@kbsi.re.kr (M.L.); leeho@kbsi.re.kr (H.U.L.) \\ 2 Department of Physics and Research Institute for Convergence of Basic Sciences, Hanyang University, \\ Seoul 04763, Korea; anchw93@hanyang.ac.kr (C.W.A.); vuthikimoanh92@gmail.com (T.K.O.V.) \\ 3 Busan Center, Korea Basic Science Institute, Busan 46742, Korea; ysjeong@kbsi.re.kr \\ 4 Department of Materials Science and Engineering, Inha University, 100 Inharo, Michuhol-gu, \\ Incheon 22212, Korea \\ 5 Department of Science Education, Jeonju University, 303 Cheonjam-ro, Wansan-gu, Jeollabuk-do 303, Korea \\ 6 Analytical Laboratory of Advanced Ferroelectric Crystals, Jeonju University, 303 Cheonjam-ro, Wansan-gu, \\ Jeollabuk-do 303, Korea \\ * Correspondence: mghahm@inha.ac.kr (M.G.H.); ek-kim@hanyang.ac.kr (E.K.K.); sspark@jj.ac.kr (S.P.)
}

Received: 31 December 2019; Accepted: 3 February 2020; Published: 10 February 2020

\begin{abstract}
In this study, the charge transport mechanism of Pd/Si-based FS-GaN Schottky diodes was investigated. A temperature-dependent current-voltage analysis revealed that the I-V characteristics of the diodes show a good rectifying behavior with a large ratio of $10^{3}-10^{5}$ at the forward to reverse current at $\pm 1 \mathrm{~V}$. The interface states and non-interacting point defect complex between the Pd metal and FS-GaN crystals induced the inhomogeneity of the barrier height and large ideality factors. Furthermore, we revealed that the electronic conduction of the devices prefers the thermionic field emission (TFE) transport, not the thermionic emission (TE) model, over the entire measurement conditions. The investigation on deep level transient spectroscopy (DLTS) suggests that non-interacting point-defect-driven tunneling influences the charge transport. This investigation about charge transport paves the way to achieving next-generation optoelectronic applications using Si-based FS-GaN Schottky diodes.
\end{abstract}

Keywords: freestanding GaN; HVPE; Schottky diodes; silicon; transport mechanism

\section{Introduction}

Gallium nitride (GaN)-related alloys hold great promise for futuristic optoelectronic applications, owing to their prominent physical properties [1-4]. To enhance the characteristics of GaN-based devices, the introduction of freestanding (FS) GaN substrates into the applicable devices is essential. To achieve high crystalline freestanding GaN crystals, a number of researchers have studied various growth methods [5-10]. Of these methods, the outstanding characteristics of hydride vapor phase epitaxy (HVPE) growth, with a high growth rate and a high crystalline growth capability, can provide significant advances to achieve freestanding $\mathrm{GaN}$ crystals with a large scalability and economic advantages [11]. However, challenges such as size limits ( $<6$ inch diameter) and manufacturing expenditure have restricted the successful introduction of HVPE freestanding GaN wafers into the commercial community [12]. Recently, we realized Si-based homoepitaxial InGaN/GaN multi-quantum well (MQW) light-emitting diodes (LEDs) with a large scalability and a desirable production cost [13-16].

To optimize the optoelectronic device using Si-based FS-GaN, it is necessary to understand the electronic transport characteristics of Schottky contact on the Si-based freestanding GaN. Their 
exploration, however, has never been inspected. Even though the literatures explained the conduction mechanism of metal/freestanding GaN, it does not provide information on S-based FS Schottky barrier diodes.

In this paper, we explored the charge transport characteristics of the Pd/Schottky diode on Si-based freestanding GaN crystals, thus elucidating how these influence GaN-based device performance.

\section{Materials and Methods}

Si-based FS-GaN crystals were prepared by the in situ removal method of a Si substrate by HVPE. The details are described in [13]. For the electrical measurement of the Schottky diodes on Si-based FS-GaN, the ohmic and Schottky contacts were achieved. A $150 \mathrm{~nm}$ thick and $3 \mathrm{~mm}$ diameter $\mathrm{Al}$ ohmic contact was constructed on the Ga-face of the Si-based freestanding GaN, using a thermal evaporator (Infinity vacuum, Seoul, Korea). Subsequently, the Schottky contacts with $1.2 \mathrm{~mm}$ in diameter were formed by an electron beam evaporator (Sorona, Seoul, Korea) using Pd ( $80 \mathrm{~nm}$ ) metal on the Ga-surface of the template, after which rapid thermal annealing in Ar ambient at $550{ }^{\circ} \mathrm{C}$ was employed. $\mathrm{Al}$ and $\mathrm{Pd}$ were deposited by a thermal evaporator and an e-beam evaporator under a vacuum level of $7 \times 10^{-6}$ Torr using a metal mask with a hole, respectively. The deposition rate of both metals is $5 \AA / s e c$. Figure 1 shows the detailed fabrication procedure. It was confirmed from the shape of the I-V curve that $\mathrm{Al}$ contact is ohmic. The electronic transport behaviors of the Schottky diodes were analyzed via temperature-dependent current-voltage (IV) characteristics in a temperature range from $220 \mathrm{~K}$ to $380 \mathrm{~K}$. The dislocation density of Si-based FS-GaN was estimated to be $1 \times 10^{6} / \mathrm{cm}^{2}$, evaluated by photoluminescence (PL) mapping analysis (not shown). Furthermore, a homemade DLTS system was used. The pulse voltage in the DLTS measurement was $-2 \mathrm{~V}$. The filling pulse widths used were $10 \mathrm{~ms}, 100 \mathrm{~ms}$, and $500 \mathrm{~ms}$, respectively. The DLTS data were obtained in the temperature range from $100 \mathrm{~K}$ to $420 \mathrm{~K}$ with increments of $0.1 \mathrm{~K}$. Various emission rates with $3.66-0.93 \mathrm{~Hz}$ were used to find the DLTS signal. The interval between the filling pulse widths was $50 \mathrm{~ms}$ under all conditions.

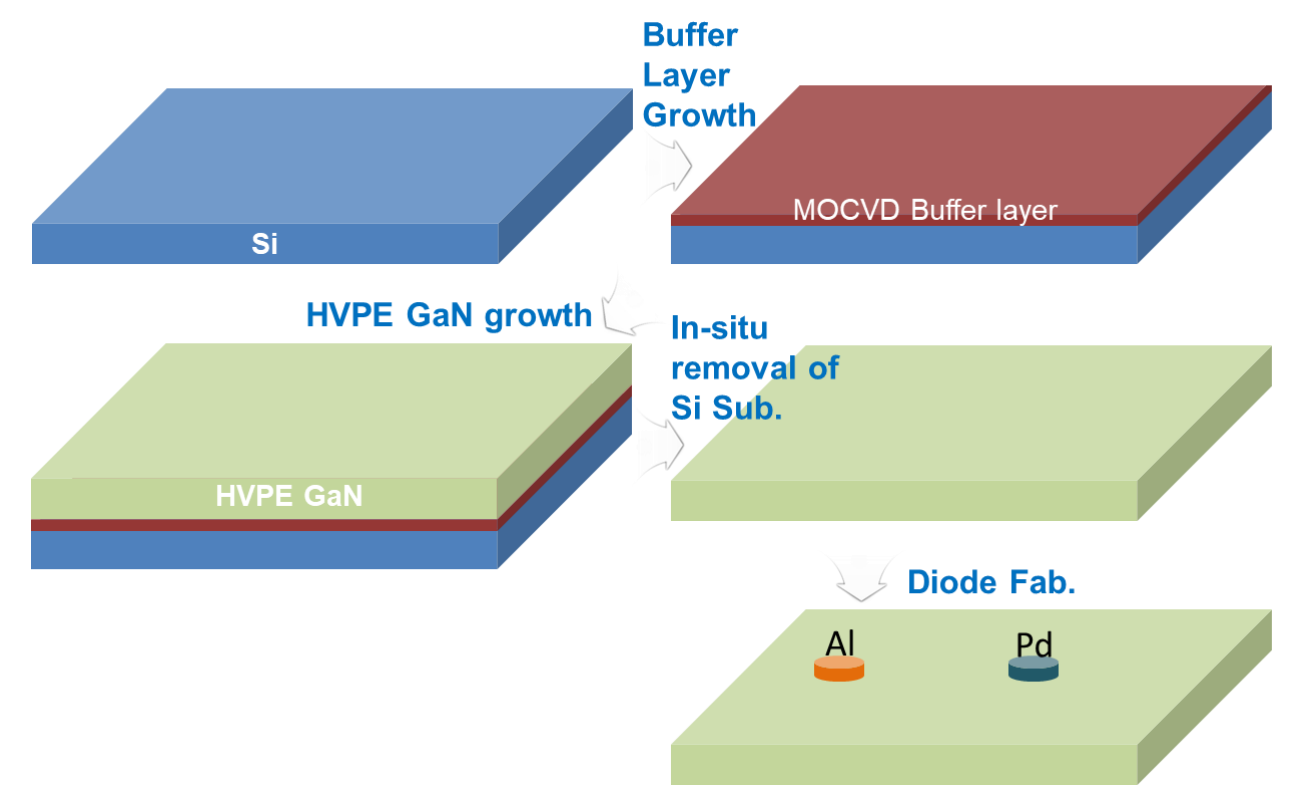

Figure 1. The fabrication procedure of the Pd/Si-based FS-GaN Schottky diode used in this study.

\section{Results and Discussion}

The temperature-dependent current-voltage (T-I-V) behaviors of the Pd/Si-based FS-GaN Schottky diodes are illustrated in Figure 2. One can clearly observe that the forward voltage in the T-I-V plots starts linearly at the initial voltage range (see the I-V curve at $300 \mathrm{~K}$ in the inset of Figure 2). However, the series resistance $\left(R_{S}\right)$ drives the distortion of the initial linearity over $0.3 \mathrm{~V}$ in the entire temperature 
range. Furthermore, it is noticeable that the charge flux increased by increasing the temperature, which is attributed to thermally generated current carriers [17]. On the other hand, the rectifying characteristics in the reverse bias clearly suggest the formation of Schottky diodes of the Pd/Si-based FS-GaN crystals in the whole temperature range. The large ratio of the forward to reverse current at $\pm 1 \mathrm{~V}$, spread over the range of $10^{0}-10^{2}$, clearly proves the good rectification behavior of the diodes.

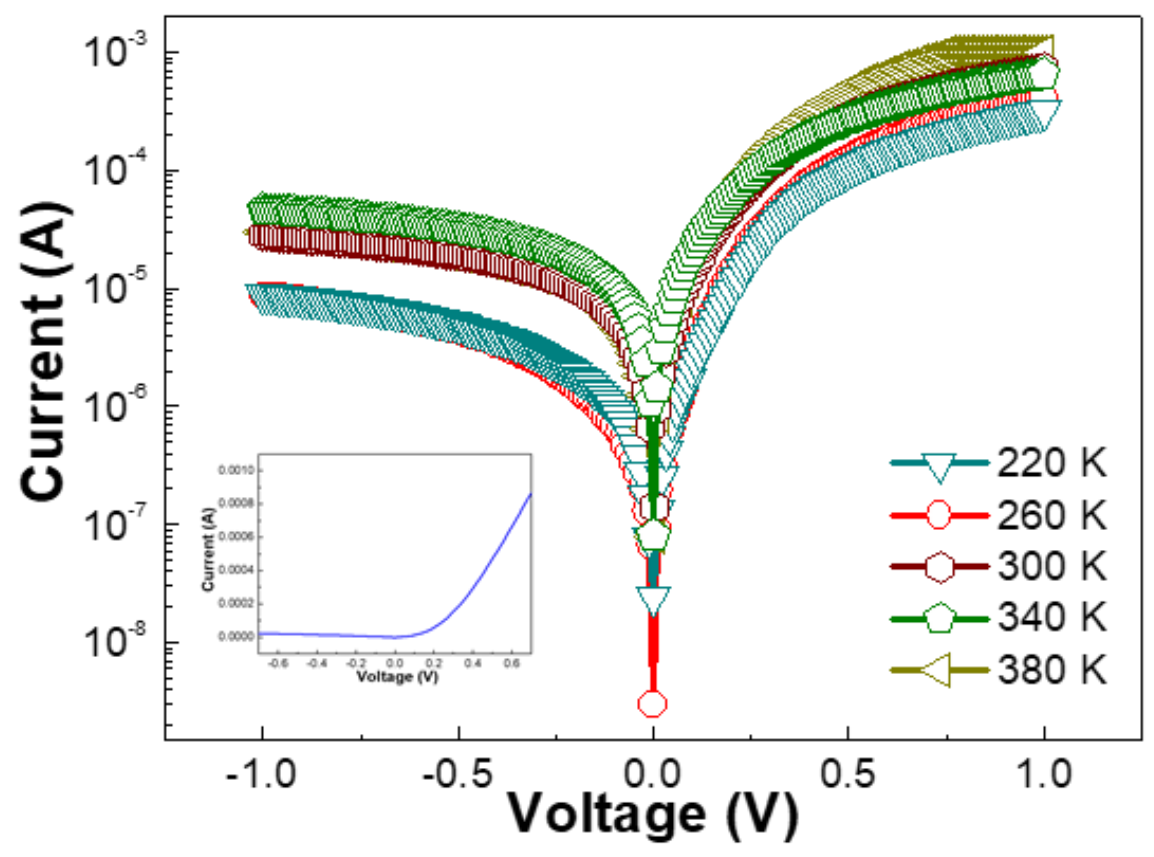

Figure 2. The $T-I-V$ characteristics of the Pd Schottky diodes based on the freestanding GaN crystals peeled off from a Si substrate.

To shed light on the electronic transport characteristics of the diodes, the thermionic emission (TE) theory was applied to extract the electrical parameters of the devices as follows [18]:

$$
\begin{gathered}
I=A A^{* *} T^{2} \exp \left(-\frac{q \Phi_{B}}{k T}\right)\left[\exp \left(\frac{q V}{n k T}\right)-1\right) \text { for } V \geq 3 k T / q \\
I_{0}=A A^{* *} T^{2} \exp \left(-\frac{q \Phi_{B}}{k T}\right)
\end{gathered}
$$

where $I_{0}$ is the saturation current, $A$ the contact area, $A^{* *}$ the Richardson constant $\left(26.4 \mathrm{~A} \cdot \mathrm{cm}^{-2} \cdot \mathrm{K}^{-2}\right.$ for n-type GaN), k the Boltzmann constant, $T$ the absolute temperature, $q$ the electron charge, $n$ the ideality factor, $\phi_{\mathrm{B}}$ the zero-bias Schottky barrier height, and V is the applied voltage.

Figure $3 a$ represents the extracted ideality factors and barrier heights of the Pd/Si-based FS-GaN Schottky diodes. It is essential to state that the inhomogeneity of the barrier height in the contact induces the gradient of the barrier height and the ideality factor of the diodes at $\sim 260 \mathrm{~K}[19,20]$. Furthermore, it was found that the drastic increment of current at $260 \mathrm{~K}$ in T-I-V curves also supports this behavior. This is commonly observable in Schottky diodes. Typically, most electrons cannot jump the barrier height in low temperatures since they do not have sufficient energy to leap it in a temperature-activated process, thus driving the lower barrier height values. However, the dominant electrons with a sufficient thermally activated energy can overcome the higher barrier height. This assigns the higher prevailing barrier height to a high temperature [21]. The TE model proposes that the ideality factors are distributed from $0.42 \mathrm{~K}$ to $0.70 \mathrm{~K}$ in the measured temperature area. Furthermore, the ideality factors in TE transport varied from $6.7 \mathrm{~K}$ to $8.2 \mathrm{~K}$ in a temperature range of 220-380 K. We attribute this to the spatially undulated barrier height in the contacts between the Pd 
contact and Si-based FS-GaN crystals, inherited from the surface defects embedded in the FS-GaN crystals [22,23]. In addition, these significant discrepancies of the ideality factors from the unity in the TE model definitely demonstrate that the charge transport mechanism of Si-based FS-GaN Schottky diodes includes another electronic tunneling conduction, such as thermionic field emission (TFE), field emission (FE), and multi-step tunneling. Given that TFE governs the tunneling conduction of the devices, the charge transport can be expressed as follows [24,25]:

$$
\begin{gathered}
I=I_{0} \exp \left(\frac{q V}{E_{00} \operatorname{coth}\left(E_{00} / k T\right)}\right)=I_{0} \exp \left(\frac{q V}{E_{0}}\right) \\
I_{0}=\frac{A A^{* *} T \sqrt{\pi E_{00} q\left(\phi_{B}-V-\xi\right)}}{k \cosh \left(E_{00} / k T\right)} \times \exp \left(-\frac{q \xi}{k T}-\frac{q\left(\phi_{B}-\xi\right)}{E_{00} \operatorname{coth}\left(E_{00} / k T\right)}\right)
\end{gathered}
$$

where $E_{00}=(q \hbar / 2)\left(\mathrm{N}_{\mathrm{D}} / \mathrm{m}^{*} \varepsilon_{\mathrm{S}}\right)^{1 / 2}, V, \xi, h, m^{*}$, and $\varepsilon_{\mathrm{S}}$ indicate the characteristic energy related to the tunneling probability of a potential barrier, the applied bias voltage, $\mathrm{E}_{\mathrm{C}}-\mathrm{E}_{\mathrm{F}}$, corresponding to $k T / q \ln \left(\mathrm{N}_{\mathrm{C}} / \mathrm{N}_{\mathrm{D}}\right)$, where $\mathrm{N}_{\mathrm{C}}$ is the effective density of states in the conduction band $\left(N_{C}=2.53 \times 10^{18} \mathrm{~cm}^{-3}\right.$ in GaN) [26], the Planck's constant, the effective mass, and the dielectric constant, respectively. $E_{0}=n k T=E_{00} \operatorname{coth}\left(E_{00} / k T\right)$. The calculated Schottky barrier heights and ideality factors were $0.68-0.91 \mathrm{eV}$ and 1.14-1.35 eV, respectively. The TFE conduction model provides a much closer value to the unity, indicating that Poole-Frenkel emission is a more plausible explanation for the tunneling mechanism of Pd/Si-based FS-GaN Schottky devices. This behavior is similar to the results of other studies $[27,28]$.

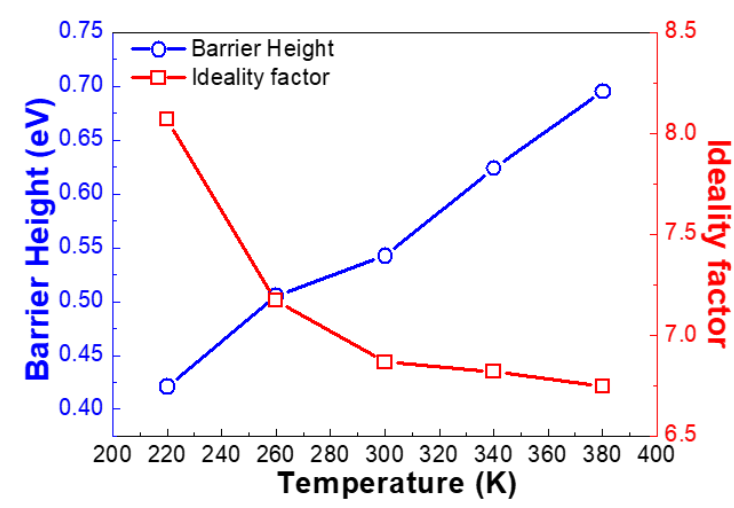

(a)

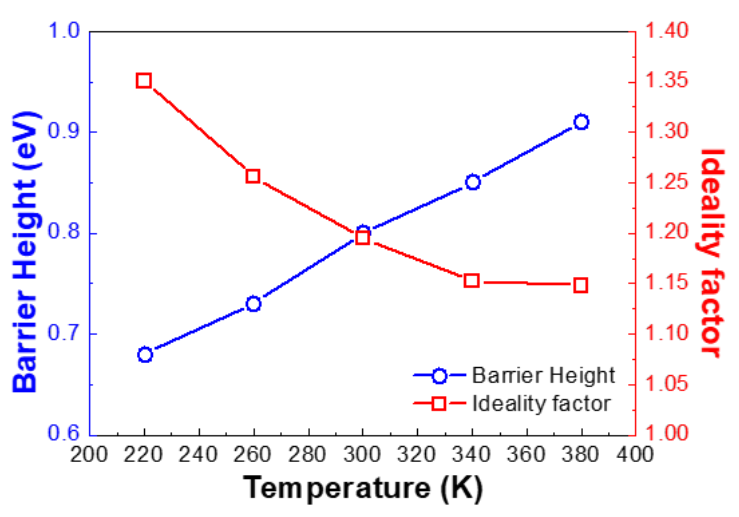

(b)

Figure 3. Plots of the barrier height and ideality factor as a function of temperature in (a) TE, and (b) the TFE model of the Si-based FS-GaN Schottky diode with Pd contact.

It is well established that tunneling, high series resistance, and interface states can give rise to the increased ideality factors or inhomogeneity of $\phi_{\mathrm{B}}$. In addition, the growth characteristics of HVPE FS-GaN crystals exhibit a large quantity of nitrogen-related surface states, $\mathrm{V}_{\mathrm{Ga}}$ point defect complex, and nitrogen anti-sites $\left(\mathrm{N}_{\mathrm{Ga}}\right)$ [29-33]. The charges can go through these tunneling sites and affect the characteristics of ideal Schottky diodes. Deep level transient spectroscopy (DLTS) measurements were employed to clarify the effects on conduction sites, as shown in Figure 4. Two deep trap levels were embedded into the FS-GaN stripped from a Si substrate, as shown in Figure 4. Table 1 summarizes the fingerprints of the electronic deep levels in the FS-GaN. The deep levels were positioned at $\sim 0.24 \mathrm{eV}$, and $\sim 1.06 \mathrm{eV}$ below the conduction band edge. Non-variation of DLTS signals vs. pulsing time confirmed that these traps were related to the non-interacting point defects [34,35]. At low climate, the carriers of the deep levels built up, and released around $260 \mathrm{~K}$, thereby augmenting the barrier heights. We must take into account that there was an abrupt increase of DLTS signals at $260 \mathrm{~K}$. This indicates that the electronic deep trap carrier influenced the charge transport in Si-based FS-GaN. This agrees with the results of the T-I-V curves in Figure 2. Therefore, we believe that deep level defects 
embedded in Si-based FS-GaN can dominate the variation in $\Phi_{\mathrm{B}}$ and $\mathrm{n}$. One can obviously observe that the intensities of DLTS signals as a function of temperature are negligible, indicative of no variation of the trap concentrations [36]. It is noticeable that the characteristics of the electronic deep level traps in Si-based FS-GaN crystals are comparable to those of conventional FS-GaN (see Table 1). This clearly proves that the FS-GaN materials extracted from the in situ removal of substrate are desirable materials for futuristic applications.

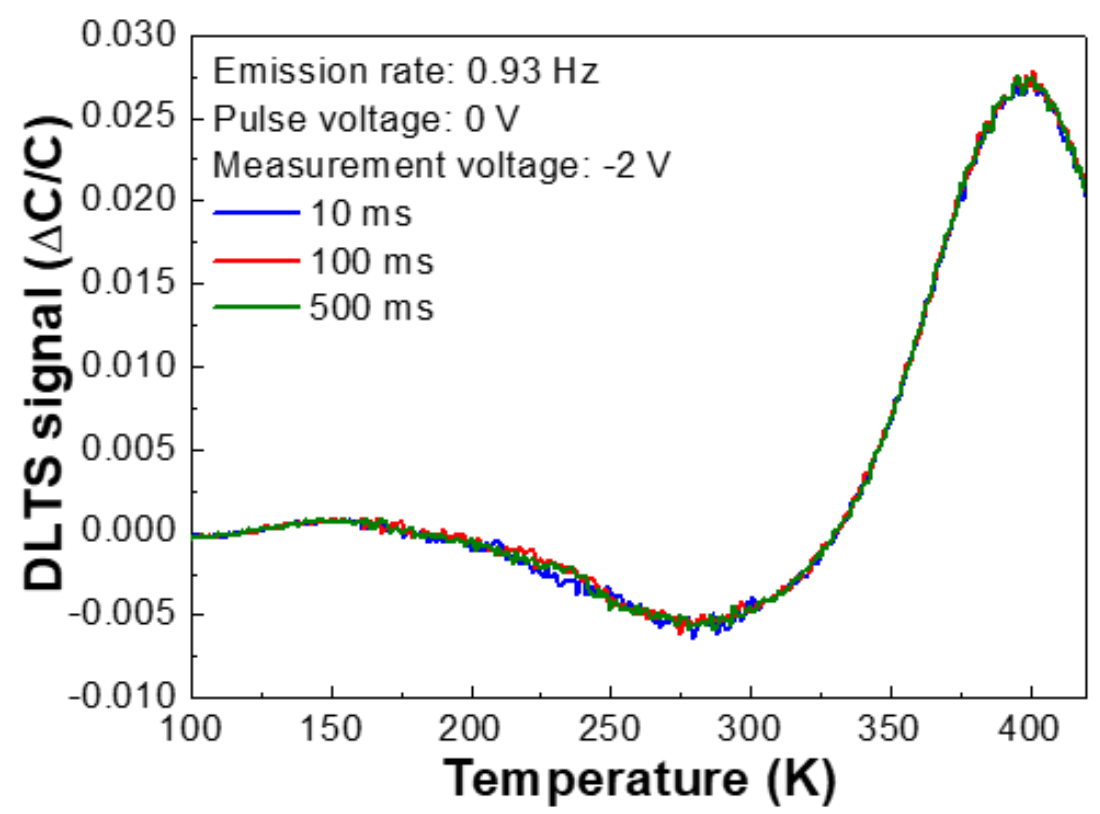

Figure 4. The DLTS spectra of Pd/Si-based GaN crystal Schottky diodes measured at the reverse voltage of $-2 \mathrm{~V}$ in the temperature range of $100-420 \mathrm{~K}$ and in the pulsing time of 100-500 ms.

Table 1. The defect parameters for the Pd/Si-based FS-GaN Schottky diodes and their comparison to other works.

\begin{tabular}{cccc}
\hline Reference & $\begin{array}{c}\text { Activation } \\
\text { Energy } \mathbf{( e V )}\end{array}$ & $\begin{array}{c}\text { Capture Cross } \\
\text { Section } \mathbf{( \mathbf { c m } ^ { 2 } \mathbf { ) }}\end{array}$ & $\begin{array}{c}\text { Trap Density } \\
\left(\mathbf{c m}^{-3}\right)\end{array}$ \\
\hline \multirow{2}{*}{ This study } & 0.24 & $1.65 \times 10^{-17}$ & $1.07 \times 10^{14}$ \\
& 1.06 & $1.76 \times 10^{-14}$ & $2.19 \times 10^{15}$ \\
\hline$[37]$ & $0.25,0.53,0.65,0.69,1.40,1.55$ & $10^{-12}-10^{-16}$ & $\sim 10^{12}-2.2 \times 10^{15}$ \\
\hline$[38]$ & $0.25,0.35,0.59,0.66,1.0$ & $6.7 \times 10^{-14}-9.0 \times 10^{-16}$ & Mid-10 \\
\hline$[39]$ & 0.6 & $2.0-10^{-17}$ & - \\
\hline
\end{tabular}

\section{Conclusions}

The current transport mechanism of Pd/Si-based FS-GaN crystal Schottky diodes was investigated using the I-V-T analysis. The TE conduction model shows a larger deviation of the ideality factors from the unity, indicative of the involvement of another transport mechanism. We proved that the carrier transport in the Schottky diodes is dominated by the TFE conduction, not only the TE one. In addition, tunneling via non-interacting point defect complex plays a key role in charge transport, which was confirmed by the DLTS measurements. The electronic characteristics of the Pd/Schottky contacts to the Si-based FS-GaN layers stand comparatively with those of conventional FS-GaN grown using other methods. This study clearly suggests that the fabrication of Pd/Si-based FS-GaN Schottky diodes can provide a promising way to achieve GaN-based futuristic devices with high performances.

Author Contributions: M.L. performed the GaN epitaxial growth, interpreted the T-I-V, and DLTS measurements, conceive the idea, and wrote the manuscript. C.W.A., and T.K.O.V. employed T-I-V, DLTS measurement. Y.J. 
and H.U.L. employed and interpreted T-I-V measurements. M.G.H., E.K.K. and S.P. supervised the project. All authors discussed and reviewed the manuscript. All authors have read and agreed to the published version of the manuscript.

Funding: This research was supported by Korea Basic Science Institute Research Grant No. C070300 and R40001 (to M. Lee) and the Basic Science Research Program through the National Research Foundation of Korea (NRF), funded by the Ministry of Education (Nos 2018R1D1A1B07042909, and 2016R1A6A1A03012069), and the Ministry of Science and ICT (NRF-2018R1A2A3074921).

Conflicts of Interest: The authors declare no conflict of interest.

\section{References}

1. Chung, K.; Beak, H.; Tchoe, Y.; Oh, H.; Yoo, H.; Kim, M.; Yi, G.-C. Growth and characterizations of GaN micro-rods on graphene films for flexible light emitting diodes. APL Mater. 2014, 2, 092512. [CrossRef]

2. Shih, H.-Y.; Shiojiri, M.; Chen, C.-H.; Yu, S.-F.; Ko, C.-T.; Yang, J.-R.; Lin, R.-M.; Chen, M.-J. Ultralow threading dislocation density in $\mathrm{GaN}$ epilayer on near-strain-free $\mathrm{GaN}$ compliant buffer layer and its applications in hetero-epitaxial LEDs. Sci. Rep. 2015, 5, 13671. [CrossRef] [PubMed]

3. Jaros, A.; Hartmann, J.; Zhou, H.; Szafranski, B.; Strassburg, M.; Avramescu, A.; Waag, A.; Voss, T. Photoluminescence of planar and 3D InGaN/GaN LED structures excited with femtosecond laser pulses close to the damage threshold. Sci. Rep. 2018, 8, 11560. [CrossRef] [PubMed]

4. Du Chene, J.S.; Tagliabue, G.; Welch, A.J.; Cheng, W.-H.; Atwater, H.A. Hot hole collection and photoelectrochemical CO2 reduction with plasmonic Au/p-GaN photocathodes. Nano Lett. 2018, 18, 2545-2550. [CrossRef] [PubMed]

5. Jachalke, S.; Hofmann, P.; Leibiger, G.; Habel, F.S.; Mehner, E.; Leisegang, T.; Meyer, D.C.; Mikolajick, T. The pyroelectric coefficient of free standing GaN grown by HVPE. Appl. Phys. Lett. 2016, 109, 142906. [CrossRef]

6. Ma, H.; He, D.; Lei, L.; Wang, S.; Chen, Y.; Wang, H. GaN crystals prepared through solid-state metathesis reaction from $\mathrm{NaGaO} 2$ and $\mathrm{BN}$ under high pressure and high temperature. J. Alloy. Compd. 2011, 509, L124-L127. [CrossRef]

7. Suihkonen, S.; Pimputkar, S.; Speck, J.S.; Nakamura, S. Infrared absorption of hydrogen-related defects in ammonothermal GaN. Appl. Phys. Lett. 2016, 108, 202105. [CrossRef]

8. Takeuchi, S.; Asazu, H.; Imanishi, M.; Nakamura, Y.; Imade, M.; Mori, Y.; Sakai, A. Dislocation confinement in the growth of Na flux GaN on metalorganic chemical vapor deposition-GaN. J. Appl. Phys. 2015, 118, 245306. [CrossRef]

9. Li, T.; Ren, G.; Su, X.; Yao, J.; Yan, Z.; Gao, X.; Xu, K. Growth behavior of ammonothermal GaN grown on nonpolar and semipolar HVPE GaN seeds. CrystEngComm 2019. [CrossRef]

10. Liu, Z.; Ren, G.; Shi, L.; Su, X.; Wang, J.; Xu, K. Effect of carbon types on the generation and morphology of GaN polycrystals grown using the Na flux method. CrystEngcomm 2015, 17, 1030-1036. [CrossRef]

11. Cich, M.J.; Aldaz, R.I.; Chakraborty, A.; David, A.; Grundmann, M.J.; Tyagi, A.; Zhang, M.; Steranka, F.M.; Krames, M.R. Bulk GaN based violet light-emitting diodes with high efficiency at very high current density. Appl. Phys. Lett. 2012, 101, 223509. [CrossRef]

12. Kelly, M.K.; Vaudo, R.P.; Phanse, V.M.; Görgens, L.; Ambacher, O.; Stutzmann, M. Large free-standing GaN substrates by hydride vapor phase epitaxy and laser-induced liftoff. Jpn. J. Appl. Phys. 1999, 38, L217. [CrossRef]

13. Lee, M.; Yang, M.; Song, K.M.; Park, S. InGaN/GaN blue light emitting diodes using freestanding GaN extracted from a Si substrate. ACS Photonics 2018, 5, 1453-1459. [CrossRef]

14. Lee, M.; Lee, H.U.; Song, K.M.; Kim, J. Significant improvement of reverse leakage current characteristics of Si-based homoepitaxial InGaN/GaN blue light emitting diodes. Sci. Rep. 2019, 9, 970. [CrossRef]

15. Lee, M.; Lee, H.; Song, K.; Kim, J. Investigation of forward tunneling characteristics of InGaN/GaN blue light-emitting diodes on freestanding GaN detached from a Si substrate. Nanomaterials 2018, 8, 543. [CrossRef]

16. Lee, M.; Ahn, C.W.; Vu, T.K.O.; Lee, H.U.; Kim, E.K.; Park, S. First observation of electronic trap levels in freestanding GaN crystals extracted from Si substrates by hydride vapour phase epitaxy. Sci. Rep. 2019, 9, 7128. [CrossRef]

17. Zou, X.; Zhang, X.; Lu, X.; Tang, C.W.; Lau, K.M. Fully vertical GaN pin diodes using GaN-on-Si epilayers. IEEE Electron Device Lett. 2016, 37, 636-639. [CrossRef] 
18. Kumar, A.; Kashid, R.; Ghosh, A.; Kumar, V.; Singh, R. Enhanced thermionic emission and low 1/f noise in exfoliated graphene/GaN Schottky barrier diode. ACS Appl. Mater. Interfaces 2016, 8, 8213-8223. [CrossRef]

19. Singh, R.; Sharma, P.; Khan, M.A.; Garg, V.; Awasthi, V.; Kranti, A.; Mukherjee, S. Investigation of barrier inhomogeneities and interface state density in $\mathrm{Au} / \mathrm{MgZnO}$ : Ga Schottky contact. J. Phys. D Appl. Phys. 2016, 49, 445303. [CrossRef]

20. Kumar, A.; Heilmann, M.; Latzel, M.; Kapoor, R.; Sharma, I.; Göbelt, M.; Christiansen, S.H.; Kumar, V.; Singh, R. Barrier inhomogeneities limited current and 1/f noise transport in GaN based nanoscale Schottky barrier diodes. Sci. Rep. 2016, 6, 27553. [CrossRef]

21. Rajpalke, M.K.; Bhat, T.N.; Roul, B.; Kumar, M.; Krupanidhi, S. Current transport in nonpolar a-plane InN/GaN heterostructures Schottky junction. J. Appl. Phys. 2012, 112, 023706. [CrossRef]

22. Reddeppa, M.; Park, B.-G.; Lee, S.-T.; Hai, N.H.; Kim, M.-D.; Oh, J.-E. Improved Schottky behavior of GaN nanorods using hydrogen plasma treatment. Curr. Appl. Phys. 2017, 17, 192-196. [CrossRef]

23. Omotoso, E.; Meyer, W.E.; Auret, F.D.; Paradzah, A.T.; Diale, M.; Coelho, S.M.; van Rensburg, P.J. The influence of high energy electron irradiation on the Schottky barrier height and the Richardson constant of Ni/4H-SiC Schottky diodes. Mater. Sci. Semicond. Process. 2015, 39, 112-118. [CrossRef]

24. Sze, S.M.; Ng, K.K. Physics of Semiconductor Devices; John Wiley \& Sons: Hoboken, NJ, USA, 2006.

25. Crowell, C. Richardson constant and tunneling effective mass for thermionic and thermionic-field emission in Schottky barrier diodes. Solid-State Electron. 1969, 12, 55-59. [CrossRef]

26. Hacke, P.; Detchprohm, T.; Hiramatsu, K.; Sawaki, N. Schottky barrier on n-type GaN grown by hydride vapor phase epitaxy. Appl. Phys. Lett. 1993, 63, 2676-2678. [CrossRef]

27. Reddy, V.R.; Reddy, N.N.K. Current transport mechanisms in Ru/Pd/n-GaN Schottky barrier diodes and deep level defect studies. Superlattices Microstruct. 2012, 52, 484-499. [CrossRef]

28. Akkal, B.; Benamara, Z.; Abid, H.; Talbi, A.; Gruzza, B. Electrical characterization of Au/n-GaN Schottky diodes. Mater. Chem. Phys. 2004, 85, 27-31. [CrossRef]

29. Mattila, T.; Nieminen, R.M. Point-defect complexes and broadband luminescence in GaN and AlN. Phys. Rev. B 1997, 55, 9571. [CrossRef]

30. Look, D.C.; Reynolds, D.; Fang, Z.-Q.; Hemsky, J.; Sizelove, J.; Jones, R. Point defect characterization of GaN and ZnO. Mater. Sci. Eng. B 1999, 66, 30-32. [CrossRef]

31. Fang, Z.-Q.; Claflin, B.; Look, D.C.; Green, D.; Vetury, R. Deep traps in AlGaN/GaN heterostructures studied by deep level transient spectroscopy: Effect of carbon concentration in GaN buffer layers. J. Appl. Phys. 2010, 108, 063706. [CrossRef]

32. Cho, H.; Kim, C.; Hong, C.-H. Electron capture behaviors of deep level traps in unintentionally doped and intentionally doped n-type GaN. J. Appl. Phys. 2003, 94, 1485-1489. [CrossRef]

33. Hacke, P.; Detchprohm, T.; Hiramatsu, K.; Sawaki, N.; Tadatomo, K.; Miyake, K. Analysis of deep levels in n-type GaN by transient capacitance methods. J. Appl. Phys. 1994, 76, 304-309. [CrossRef]

34. Hierro, A.; Arehart, A.; Heying, B.; Hansen, M.; Speck, J.; Mishra, U.; DenBaars, S.; Ringel, S. Capture kinetics of electron traps in MBE-grown n-GaN. Phys. Status Solidi B 2001, 228, 309-313. [CrossRef]

35. Pak, S.W.; Lee, D.U.; Kim, E.K.; Park, S.H.; Joo, K.; Yoon, E. Defect states of a-plane GaN grown on r-plane sapphire by controlled integration of silica nano-spheres. J. Cryst. Growth 2013, 370, 78-81. [CrossRef]

36. Peta, K.R.; Park, B.-G.; Lee, S.-T.; Kim, M.-D.; Oh, J.-E.; Kim, T.-G.; Reddy, V.R. Analysis of electrical properties and deep level defects in undoped GaN Schottky barrier diode. Thin Solid Film 2013, 534, 603-608. [CrossRef]

37. Duc, T.T.; Pozina, G.; Janzén, E.; Hemmingsson, C. Investigation of deep levels in bulk GaN material grown by halide vapor phase epitaxy. J. Appl. Phys. 2013, 114, 153702. [CrossRef]

38. Fang, Z.; Look, D.C.; Visconti, P.; Lu, C.; Wang, D.; Morkoç, H.; Park, S.; Lee, K. Characteristics of deep traps in freestanding GaN. MRS Online Proc. Libr. Arch. 2001, 693. [CrossRef]

39. Tokuda, Y.; Matuoka, Y.; Yoshida, K.; Ueda, H.; Ishiguro, O.; Soejima, N.; Kachi, T. Evaluation of dislocation-related defects in GaN using deep-level transient spectroscopy. Phys. Status Solidi C 2007, 4, 2568-2571. [CrossRef]

(C) 2020 by the authors. Licensee MDPI, Basel, Switzerland. This article is an open access article distributed under the terms and conditions of the Creative Commons Attribution (CC BY) license (http://creativecommons.org/licenses/by/4.0/). 